\title{
Imagens em movimento e a produção de presença em Misanthrofreak ${ }^{1}$
}

\section{Moving images and the production of presence in Misanthrofreak}

\author{
Rodrigo Desider Fischer ${ }^{2}$, \\ Roberta Kumasaka Matsumoto ${ }^{3}$ \\ Glauber Gonçalves de $\mathrm{Abreu}^{4}$
}

\section{Resumo}

Neste artigo, por meio do estudo do espetáculo Misanthrofreak, de Rodrigo Fischer (2014), buscamos apontar de que modo as imagens em movimento podem se constituir como agenciadoras na produção de presença. Desde o final do século XIX, primeiramente o cinema e, em seguida, o vídeo têm estimulado e modificado nossa percepção, nossa relação com o mundo e, consequentemente, nosso entendimento sobre o trabalho do ator, a presença, os desdobramentos do tempo e do espaço cênicos e, neste sentido, os limites das artes da cena. Apresentamos os conceitos de cineficação e fotogenia para descrever momentos do processo criativo de Misanthrofreak e demonstrar a despossessão do corpo orgânico em relação às imagens e objetos, desestabilizando certo núcleo de produção de presença em cena e, com isso, a própria noção de teatralidade.

\section{Palavras-chave}

Teatro; imagem em movimento; cineficação; fotogenia; presença.

\begin{abstract}
Based on the project Misanthrofreak, directed by Rodrigo Fischer (2014), the paper aims to analyze how the moving images can be constituted as an agency in the production of presence. Since the film was created, the audiovisual materials have been changing our perception and our relation to the world. Hence, our understanding of acting, presence, the conception of time-space and the boundary of the performing arts. We'd like to present the concept of cinefication and photogeny to describe the creative process of Misanthrofreak and also to show the organic body's dispossession in relation to images and objects in order to destabilize the focus of production of presence onstage, and consequently the concept of theatricality.
\end{abstract}

\section{Keywords}

Theatre; moving image; cinefication; photogeny; presence.

${ }^{1}$ Artigo foi desenvolvido a partir da Tese de Doutorado Uma poética entre o cinema e o teatro: reflexões sobre a presença e a atuação cênica na obra de John Cassavetes, de Rodrigo Desider Fischer. Outra abordagem do espetáculo pode ser vista no artigo Variações sobre teatro e audiovisual de Roberta K. Matsumoto.

2 Pesquisador colaborador e bolsista PNPD do Programa de Pós-Graduação em Artes Cênicas da Universidade de Brasília. Doutor em Processos Composicionais para a Cena pela Universidade de Brasília e City University of New York com uma investigação sobre o cinema de John Cassavetes e sua contribuição para o trabalho do ator. Atualmente realiza Pós-Doutorado no Programa de PósGraduação em Artes Cênicas pela Universidade de Brasília e no Departamento de Performance Studies da New York University.

${ }^{3}$ Professora do Departamento de Artes Cênicas, do Programa de Pós-Graduação em Artes Cênicas e do Programa de Pós-Graduação em Arte da Universidade de Brasília (UnB). Doutora em Antropologia Fílmica pela Université Paris X - Nanterre, coordena o Laboratório Imagens e $(m)$ Cena e o Grupo de Pesquisa de mesmo nome, no qual são desenvolvidas pesquisas que problematizam as fronteiras entre teatro, vídeo, cinema, dança, performance e instalação, os processos criativos e as metodologias de pesquisa nas Artes Cênicas.

${ }^{4}$ Professor do curso de Licenciatura em Teatro do Instituto Federal Fluminense. Licenciado em Educação Artística e Mestre em Arte pela Universidade de Brasília, desenvolve pesquisa de Doutorado sobre a noção de presença na cena contemporânea, sob orientação da professora Dra. Roberta K. Matsumoto. Escreveu o livro Canteiro de Obras: notas sobre o teatro candango (2012), no qual apresenta e analisa os primeiros cinquenta anos da produção teatral de Brasília. Utiliza o pseudônimo Glauber Coradesqui. 
O objetivo deste artigo é investigar de que modo atuação e imagem em movimento se afetam mutuamente para gerar presença e de que modo impactam o processo criativo do ator-performer ${ }^{5}$ no contexto do teatro performativo (Féral, 2012; 2015). Nossa questão se desenvolve a partir do estudo do espetáculo solo Misanthrofreak ${ }^{6}$, criado pelo ator e diretor Rodrigo Fischer em 2014, na cidade de Nova York, e apresentado em 20 cidades de diversas regiões brasileiras e no exterior.

Em Misanthrofreak, corpo, imagem e objetos são dispostos na mesma categoria e assumidos como "coisas" (Lepecki, 2012) que se constituem mutuamente, podendo afetar e ser afetadas. Em outras palavras, Fischer busca nesta obra potencializar a presença cênica tanto pela materialidade do corpo quanto pela materialidade das imagens e dos objetos. Interessa-se pela produção de efeitos de presença que oscilam entre a performatividade e a teatralidade a partir da interação com outras mídias, em especial a imagem em movimento. Essa imagem, por sua vez, agencia a produção de efeitos de sentido e de presença em cena, evidenciando, assim, o deslocamento do estatuto do ator-performer, cujo corpo orgânico deixa de exercer função nuclear no espetáculo.

Por efeitos de presença, no caso específico desse estudo, entendemos o impacto das imagens sobre os corpos numa intensidade tal que seja capaz de aflorar afetos. Os afetos, numa perspectiva spinoziana, constituem "as afecções do corpo, pelas quais sua potência de agir é aumentada ou diminuida, estimulada ou refreada, e, ao mesmo tempo, as idéias dessas afecções" (Spinoza, 2009: 98). Essa perspectiva abrange a relação dos próprios entes da cena, orgânicos ou inorgânicos (objetos, imagens etc.), entre si.

\footnotetext{
${ }^{5}$ A proposta de usar essa denominação específica visa a não confusão com o termo em inglês performer, utilizado muitas vezes como sinônimo de ator. Já em português, a palavra performer se associa mais à performance ou quando nos referimos àquele que age dentro do contexto do teatro performativo. No entanto, por mais que a palavra ator se dirija àquele que age em nome de outro e performer ao que age em seu próprio nome, utilizá-los apenas nesse âmbito seria simplificar excessivamente tais conceitos. Por isso, a opção por ator-performer tem também o intuito de enfatizar o constante trânsito entre o eu o outro.

${ }^{6}$ Video disponível em: https://vimeo.com/104848375 (senha: grupodesvio)
} 
Por imagem em movimento entendemos quaisquer imagens produzidas por tecnologias de captura do mundo sensível a partir de um número específico de quadros por segundo de forma que, ao serem projetadas, nos dão a ilusão de que é o próprio passar do tempo, sem interrupções, que estamos a contemplar.

Em Misanthrofreak, o uso de imagens irá se situar numa busca de entender a imagem em movimento por um viés que potencialize mais o tempo do que um sequenciamento lógico de movimento. Essa diferenciação pode ser problematizada a partir das ideias de Deleuze a respeito da imagem-movimento e da imagemtempo.

O sequenciamento de imagens em movimento que prioriza uma lógica narrativa, condicionada principalmente ao movimento e ao espaço, é o que Deleuze (2006; 2009) chama de imagem-movimento. Nesse cinema, o tempo se constitui por meio de cortes racionais, ou seja, por uma montagem em que planos sucessivos e sequenciais imprimem uma sensação de movimento e continuidade espacial.

Os cortes racionais determinam sempre relações comensuráveis entre séries de imagens e constituem por isso toda a rítmica e harmonia do cinema clássico, ao mesmo tempo que integram as imagens associadas numa totalidade sempre aberta. O tempo é, pois, essencialmente o objeto de uma representação indireta, segundo as relações comensuráveis e os cortes racionais que organizam a seqüência ou o encadeamento das imagensmovimento (Deleuze, 2006: 273).

Já o cinema cujo tempo se constitui por meio de cortes irracionais - ou seja, cortes que não priorizam o sequenciamento lógico de imagens - é denominado imagem-tempo. Segundo Deleuze, esse cinema teria sido inaugurado com o Neorrealismo italiano e a Nouvelle-vague francesa, ambos marcados pela temporalização da imagem. Com isso ele quer dizer que:

Já não há, pois, associações por metáfora ou metonímia, mas reencadeamento sobre a imagem literal; já não há encadeamento de imagens associadas, mas apenas reencadeamentos de imagens independentes. Em vez de uma imagem depois da outra, há uma imagem mais a outra, e cada plano é desenquadrado em relação ao enquadramento do plano seguinte (Deleuze, 2006: 274). 
Para o autor, a crise do movimento libera o tempo, que deixa de ser algo indireto e se torna a própria imagem. Da mesma forma, entendemos que a crise do corpo orgânico do ator-performer em Misanthrofreak libera as imagens e os objetos, que se tornam eles próprios produtores de presença, como veremos mais adiante. Todavia, é importante considerar que, apesar de se priorizar o uso de imagens que poderiam contribuir para a ampliação da presença em cena, nem todas elas concorrem para isso. Somente as imagens que condensam potencialidade como imagem-tempo, transcendendo a sua própria representação objetiva, possibilitam afetos e, consequentemente, produção de presença. Por este motivo, ao criar as imagens do espetáculo, buscou-se expandir os efeitos de presença próprios à imagem de forma a aproximá-las do conceito de imagem-tempo.

Assim, buscando apontar como as imagens em movimento podem se constituir como agenciadoras na produção de presença, num primeiro momento, pontuamos a visão de alguns encenadores do século $\mathrm{XX}$ sobre a relação da imagem em movimento e o teatro para, em seguida, fazermos uma breve descrição do espetáculo e realizarmos a análise de cenas do espetáculo Misanthrofreak entrelaçando as noções de cineficação, fotogênia e efeito de presença.

\section{Teatro e Cinema: aproximações}

Numa possível linha do tempo do teatro ocidental, foi a partir da crise do drama moderno que o teatro passou a estabelecer seus primeiros diálogos com o cinema - momento em que a arte teatral se distanciou da normativa textocêntrica e propôs-se a dialogar com outras artes - e, hoje, no contexto do teatro performativo, a influência deliberada de um sobre o outro está deflagrada. Dentre as inúmeras apropriações precursoras do cinema nas montagens teatrais do início do século XX, vale destacar o trabalho de Erwin Piscator e Vsevolod Meyerhold. Piscator faz uso da projeção em cena a fim de apoiar seu discurso político de duas maneiras: no que ele denomina de filme dramático e filme comentário. Segundo a definição do encenador:

O filme dramático intervém no desenvolvimento da ação. Ele substitui a cena falada. Lá onde o teatro perde tempo em expli- 
cações e diálogos, o filme esclarece situações através de algumas imagens rápidas. Somente o mínimo necessário [...] O filme de comentário acompanha a ação como um coro. Ele se dirige diretamente ao espectador, o interpela [...] O filme de comentário atrai a atenção do espectador sobre momentos importantes da ação [...] Ele critica, acusa, precisa datas importantes (apud Monteiro, 2011:27).

Já Meyerhold, amplamente influenciado pelo cinema, sobretudo por seu amigo e aluno Sergei Eisenstein, considerou a sétima arte como uma camada que multiplica o sentido da cena, distanciando-se de qualquer utilização ilustrativa ou figurativa. Utilizou não apenas projeções fílmicas em suas montagens, mas aproximou-se do cinema também no que se refere à apropriação das especificidades da linguagem cinematográfica, marcadamente no sentido de pensar as potencialidades da imagem, independente de qualquer discurso verbal. A imagem passou a ocupar, então, especialmente a partir do movimento simbolista, um lugar importante no teatro, pois ampliava novas possibilidades espaço-temporais para a cena.

Ora, se com o surgimento do cinema alguns encenadores passaram a atuar em novas possibilidades para a cena teatral, como as experiências mencionadas de Piscator ou Meyerhold, é com a invenção do vídeo que outras inúmeras formas viriam a revitalizar a estética cênica. Ao aparecer na década de 1950, inicialmente com a performance art de Nam Jun Paik ${ }^{7}$, o vídeo reconfigurou radicalmente questões de tempo e espaço nas artes da cena. Viabilizou não só a multiplicação de imagens, como também o recorte espacial e corporal, a condução do espectador para pontos específicos da cena, o diálogo e complemento para os demais elementos cenográficos e, sobretudo, a "busca de uma narrativa híbrida, que possibilite uma forma mais sensorial à recepção do evento teatral” (Barone, 2009:109).

Dessa maneira, as imagens videográficas no teatro, não são necessariamente pensadas a partir de uma lógica própria, que possibilite a produção de sentidos de forma isolada, mas, fundamentalmente, por seu agenciamento com a cena buscando outras formas de composição do espaço e do tempo do acontecimento cênico.

${ }^{7}$ Artista sul coreano considerado um dos precursores da videoarte, criador de um dispositivo portátil nos anos 60 para a gravação de seus vídeos. 
É nesse sentido que caminhou a composição do espetáculo Misanthrofreak, na qual o vídeo é inserido de forma que a imagem produza efeitos de presença, fazendo aflorar afetos para além de qualquer processo de significação. Georges Didi-Huberman $(1998 ; 2013)$ ao refletir sobre a obra de arte e a imagem na contemporaneidade também explicita essa abordagem da imagem:

\begin{abstract}
Ela [imagem] exige, pois, um olhar que não se aproximaria apenas para discernir e reconhecer, para nomear a qualquer preço o que percebe - mas que primeiramente se afastaria um pouco e se absteria de clarificar tudo de imediato. Algo como uma atenção flutuante, uma longa suspensão do momento de concluir, em que a interpretação teria tempo de se estirar em várias dimensões, entre o visível apreendido e a prova vivida de um desprendimento. Haveria assim, nessa alternativa, a etapa dialética - certamente impensável para um positivismo - que consiste em não apreender a imagem e deixar-se antes ser apreendido por ela: portanto, em deixar-se desprender do seu saber sobre ela. O risco é grande, sem dúvida. É o mais belo risco da ficção. Aceitaríamos nos entregar às contingências de uma fenomenologia do olhar, em perpétua instancia de transferência ou de projeção (Didi-Huberman, 2013: 23-24).
\end{abstract}

Entendemos que Didi-Huberman, ao contestar a tradição iconológica e cientificista das imagens, não nega sua dimensão representacional e sua potencialidade para produção de sentidos, mas reforçar a ideia de que os efeitos de presença produzidos pela imagem que obrigam a conversão do olhar para que a experiência estética possa se dar. Antes de olhar uma imagem e se prender ao seu significado figurativo, trata-se de permitir que ela nos olhe, de forma a sermos apreendidos por ela e seus múltiplos significantes. Não "há que escolher entre o que vemos e o que nos olha. Há apenas que se inquietar com o entre. Há apenas que dialetizar.” (Didi-Huberman, 1998: 71).

\title{
Misanthrofreak: breve descrição
}

Misanthrofreak é um espetáculo solo sobre a fuga, o fracasso e a misantropia. Teve como ponto de partida o questionamento "o que pode um corpo?", um questionamento espinosiano apresentado no Escólio da Preposição 2 da Terceira Parte da Ética: "O fato é que ninguém determinou, até agora, o que pode o corpo, isto é, a experiência a ninguém ensinou, até agora, o que o corpo - [...]- 
VIS

Revista do Programa de Pós-graduação em Arte da UnB

pode e o que não pode fazer" (Spinoza, 2009: 101). Como tenativa de resposta, buscou instalar uma certa crise do corpo como núcleo imantado da produção de presença, fazendo ressaltar o agenciamento com outros elementos da cena, sobretudo as imagens em movimento.

O espetáculo não trata de uma representação do malogro de uma persona de ficção. É, antes, o erro enquanto performação presente, deliberada, já não a partir exclusivamente da figura de ficção como também do ator ele mesmo, que não só se faz matéria como também inventa a dinâmica do espetáculo operando toda a sua mecânica (luz, som, vídeo).

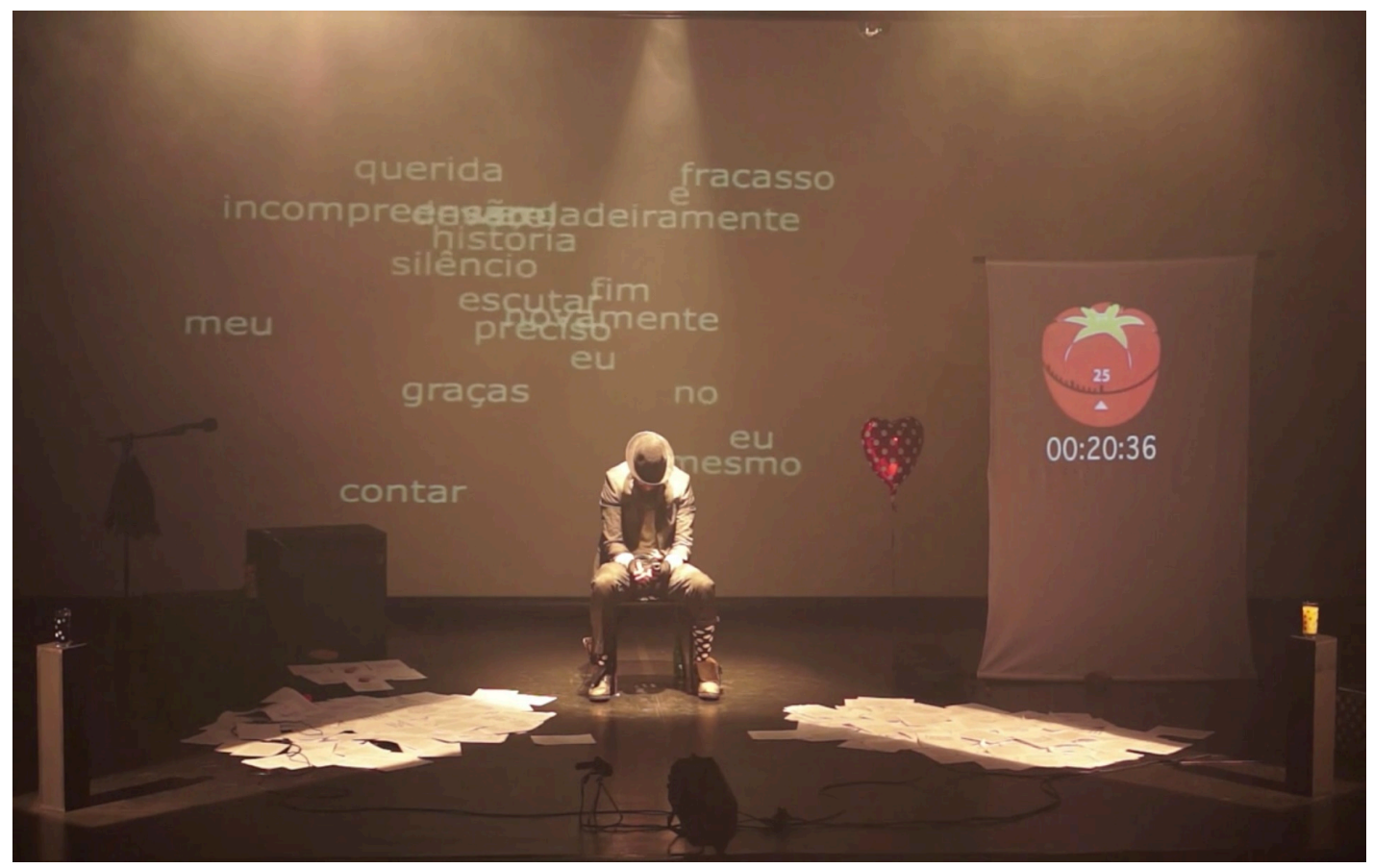

Figura 1. Cena de abertura do espetáculo Misanthrofreak. ${ }^{8}$

Logo na entrada da sala (Figura 1), nos confrontamos com uma pessoa sentada no meio do espaço cênico e em meio a diferentes objetos: malas-baús; balão em forma de coração; papeis espalhados pelo chão; duas imagens - uma, projetada em uma tela menor colocada na lateral direita apresentando a figura do

\footnotetext{
${ }^{8}$ Todas as imagens inseridas no artigo são capturas de tela da filmagem de Misanthrofreak realizada no Teatro SESC Paulo Autran em Taguatinga, no dia 13 de setembro de 2014. 
pomodoro-duração ${ }^{9}$ (cronometro em forma de tomate) que marca a passagem do tempo, e outra, projetada na parede de fundo do palco fazendo dançar palavras (fracasso, história, querida, eu, precisarei, escutar, silêncio, fim, novamente etc.) que, ao mesmo tempo em que significam (códigos de linguagem) e nos lançam questões que irão se materializar ao longo do espetáculo, fogem a uma compreensão definitiva, pois multiplicam as possibilidades de sentido.

Assim, nesse início, contemplamos uma pessoa entre dois módulos localizados nas extremidades laterais do palco: à direita, em cima de um deles, há um copo de suco iluminado; no outro extremo, à esquerda, há um copo de Coca-Cola. A projeção do cronômetro propõe a possível tensão temporal, enquanto a outra projeção expõe a confusão mental advinda da necessidade de escolha, questão fundante do espetáculo, e que neste momento se materializa na dúvida entre o suco e o refrigerante.

Projeções de imagens em movimento estão presentes ao longo de todo o espetáculo das mais diversas maneiras: desde abstrações poéticas, paisagens visuais, textos escritos, delimitações espaciais, passagem de tempo, até seu uso mais convencional de delimitação do quadro a ser visto, principalmente com o close-up e os planos de detalhe. A utilização das imagens projetadas, conforme exposto anteriormente, partiu do princípio de que elas devem integrar e ampliar a cena, expandindo o espaço e o tempo teatral em virtude de sua capacidade de produzir presença.

Também, desde o início da obra, instaura-se um lugar no qual a relação entre "orgânicos" e "inorgânicos" não se encontra mais hierarquizada, ou seja, humanos deixando de subjugar os objetos assim como objetos deixando de subjugar os humanos. Em 9 coisas sobre coisas e performance, André Lepecki (2012) - de forma semelhante a Didi-Huberman na discussão anterior - desloca a relação en-

${ }^{9}$ Criada nos anos 80 por Francesco Cirillo, a técnica pomodoro é uma forma de gerenciar o tempo no que diz respeito à produtividade, assumindo a pausa como seu principal elemento. Em termos práticos, o tempo é gerenciado entre 25 minutos de produção (trabalho ou estudo) e 5 minutos de pausa. Disponível em: http://ramonkayo.com/wpcontent/uploads/2014/03/PomodoroTechnique.pdf Acesso em: 09 de janeiro de 2014. 
tre sujeito e objeto, pensando não apenas na possibilidade de o sujeito afetar o objeto, mas também na sua capacidade de ser afetado por ele. Para Lepecki (2012: 94), "ao produzirmos objetos, produzimos dispositivos que subjugam e diminuem a nossa própria capacidade de produzir subjetividades. Na medida em que produzimos objetos acabamos sendo produzidos por eles”. Partindo do princípio de dispositivo do filósofo italiano Giorgio Agamben, Lepecki propõe que os objetos, ao serem desconectados de sua utilidade e significação cotidiana ou mercadológica, "revelam a sua capacidade liberadora, a sua capacidade de escapar totalmente de dispositivos de captura" (Lepecki, 2012: 96). No seu entender, é preciso pensar tanto sujeito como objeto enquanto "coisa".

Chamo essa força des-possessiva e deformadora que todo objeto exerce sobre o sujeito de "coisa". Talvez tenhamos de extrair algo dessa força despossessiva, aprender de que maneira sujeitos e objetos podem se tornar menos sujeitos e menos objetos e mais coisa (Lepecki, 2012: 96 - aspas do autor).

Ainda de acordo com Lepecki (2012: 97), a "coisa" liberta os elementos orgânicos (sujeitos) e inorgânicos (objetos) de uma "força subjugadora chamada dispositivo-mercadoria - força que esmaga a todos num modo da vida empobrecido, ou triste, ou dócil, ou limitado, ou utilitário". Apesar de Lepecki considerar a "coisa" a partir da dança e da performance, entendemos que o teatro performativo (Féral, 2008) também viabiliza essa relação, uma vez que este trabalha a materialidade privilegiando o deslocamento dos códigos ao invés da representação.

A composição de Misanthrofreak se dá, portanto, a partir de um trabalho de ator que explora as materialidades do corpo, da imagem e dos objetos baseado na compreensão de que corpo, imagens, objetos seriam todos "coisa", ou seja, objetos livres do utilitarismo e subjetividade não mais "definida pela posse que o sujeito tem de si mesmo e dos seus objetos" (Moten apud Lepecki, 2012: 96). Essa experimentação constitui o próprio acontecimento teatral desse espetáculo, no qual teatralidade e performatividade são empenhadas numa dinâmica de oscilação que se sustenta pela retirada do corpo orgânico de um suposto núcleo produtor de presença. 
Além de trazer em seu bojo esse princípio, a encenação de Misanthrofreak - assim como as imagens escolhidas para compô-la - enfatiza a potência de planos e cenas isoladamente, sem se ater necessariamente à sua junção especificamente, aproximando-se, assim, do que Deleuze (2006) chamou de imagem-tempo. Mais do que objetivar a construção de uma obra linear, mantendo a unidade entre a ação, o tempo e o espaço, a encenação busca entender as possíveis relações entre "coisas" - corpos e imagens - de modo que tais relações multipliquem as camadas temporais de cada cena.

Estabelece-se, então, um movimento, não do ator, nem das imagens, nem dos sons de respiração e ventania que vão crescendo, mas dos agenciamentos do ator com as imagens, com os sons, com todas as outras coisas - boneca inflável, estalinhos, pedras, sonoridades - que vão se constituindo e gerando acontecimentos durante sessenta minutos. Mas qual a direção desse movimento? Qual a relação entre esses acontecimentos? Não há intenção de construir uma obra linear, mantendo a unidade entre a ação, o tempo e o espaço, mas de constituir a encenação por meio de experimentações que colocam em jogo as possíveis relações entre coisas de modo a multiplicar as camadas temporais e espaciais de cada cena e também propiciar o "deslizamento de sentido" (Féral, 2008: 205). Somos, assim, convidados a compartilhar desses mundos que são inventados e reinventados a cada instante e que fogem a uma captura definitiva.

Ainda que, nessa abertura, as imagens se apresentem em suas formas mais reconhecíveis ou mais comumente utilizadas - uma ilustração ou uma "explicação" da cena, supostamente acionada por um operador de vídeo -, ao longo do espetáculo compreendemos que as imagens são geradas pelas conexões do próprio ator em cena com as coisas: computador e software Isadora ${ }^{10}$, controle remoto tipo Wii, mini câmera instalada na cabeça de um boneco. Cabe ressaltar que há imagens que foram pré-gravadas e cuja reprodução é realizada pelo controle re-

\footnotetext{
${ }^{10} \mathrm{O}$ software Isadora foi desenvolvido pelo programador e coreógrafo Mark Coniglio que permite não apenas trabalhar com o mapeamento de projeções, mas também propicia a integracão e a relacão de todas instancias tecnológicas num mesmo programa.
} 
VIS

Revista do Programa de Pós-graduação em Arte da UnB

moto, assim como há imagens que são realizadas simultaneamente ao momento em que são projetadas.

\section{Cineficação e composição de cenas}

Para a pesquisadora Béatrice Picon-Vallin $(2001$; 207), "o teatro hoje é totalmente 'cineficado"”. Picon-Vallin sustenta que essa influência acontece de dois modos, os quais denomina de cineficação externa e cineficação interna. O primeiro resulta justamente da utilização de imagens projetadas ou por meio de outros aparatos como o vídeo. O segundo "diz respeito à utilização de modelos técnicos do cinema e da pesquisa de seu equivalente teatral" (Picon-Vallin, 2001: 207). Em Misanthrofreak, ambos os modos são praticados na construção da dramaturgia da obra.

Um dos momentos mais complexos em Misanthrofreak, e que permite exemplificar as várias apropriações de cineficações externas e internas concomitantemente, é a cena em que ocorrem os agenciamentos entre bonecos, ator e duas câmeras que dispõem inúmeros pontos de vistas da cena. Corpo-urso, corpoboneca, corpo-casa, corpo-ator, corpo-imagem etc.: "coisas" que, ao se afetarem mutuamente, se constituem e se transformam.

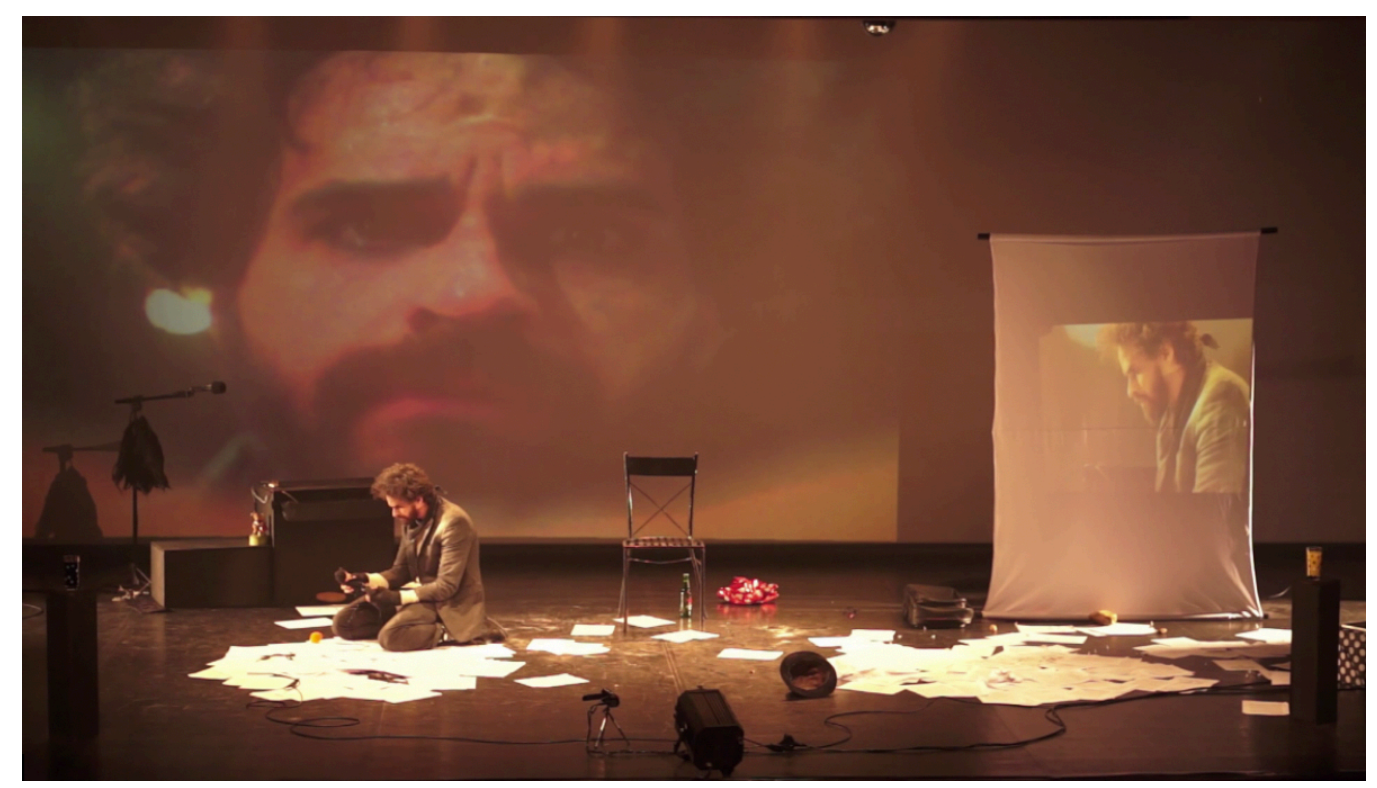

Figura 2. Cena com os bonecos em Misanthrofreak. 
Sob a ótica cinematográfica, a cena tem início com o plano-geral de todo o palco, que é também a visão global do espectador. Dentro desse quadro (Figura 2), por meio de duas telas de projeção, delimitam-se mais dois planos: um planomédio lateral do ator, com uma câmera posicionada na boca de cena, e um closeup na tela maior ao fundo, demarcado por uma câmera instalada na cabeça do boneco. Além das imagens ao vivo capturadas com essas duas câmeras, há também imagens pré-gravadas em alternância com as imagens da câmera subjetiva ${ }^{11}$ do boneco, projetadas na tela ao fundo. O espectador dispõe, assim, de três ângulos de visão da mesma cena, em estrutura promovida no âmbito da cineficação externa por meio de aparatos tecnológicos: telas, projetores e câmeras. Já a relação estabelecida entre a tela maior, a tela menor e as ações do ator com os bonecos viabilizam um jogo cênico-fílmico que multiplica as camadas espaçotemporais do espetáculo. Esse jogo acontece como um modo de cineficação inter$n a$, em que a expressão cinematográfica encontra seus equivalentes na expressividade do teatro.

Logo, em Misanthrofreak, as interferências cinematográficas não se limitam a projeções no palco, mas se dão na relação com as ações do ator e em suas possíveis multiplicações espaço-temporais e produção de presença, conforme pode-se observar na sequência das imagens retiradas da cena aqui analisada (Figura 3). No caso específico dessa cena, das muitas apropriações cinematográficas, o jogo com raccord ${ }^{12}$ de movimento entre as ações do ator e sua continuidade nas telas multiplicou os pontos de vista do espectador.

\footnotetext{
${ }^{11}$ A câmera subjetiva é aquela assume o ponto de vista de uma das personagens ou do próprio diretor do filme.

${ }^{12}$ Raccord é um recurso de montagem cinematográfico. Para Jacques Aumont (2003: 251) é uma prática "de montagem na qual as mudanças de planos são, tanto quanto possível, apagadas como tais, de maneira que o espectador possa concentrar toda sua atenção na continuidade da narrativa visual". Há diversos tipo de raccord, entre eles, o raccord de movimento, em que o movimento de um mesmo objeto ou corpo parece manter continuidade de um plano para outro.
} 


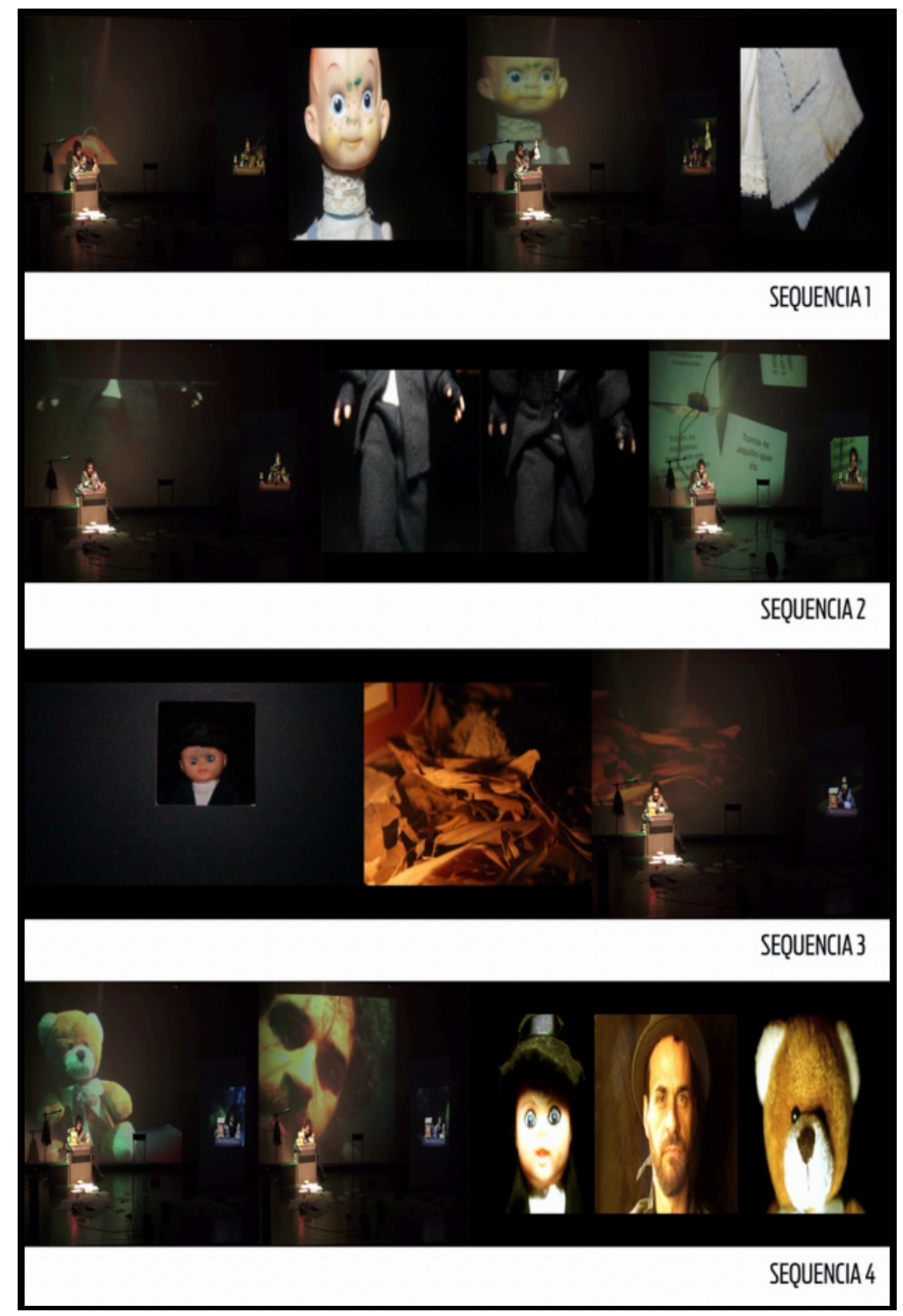

Figura 3. Cena com os bonecos em Misanthrofreak

Na Sequência 1, a ação de movimentar a boneca para cima como um voo, realizada no palco, se multiplica com a imagem ao vivo projetada na tela da direita e pelas imagens pré-gravadas com diversos planos da boneca, em alternância ao captado ao vivo pela câmera subjetiva instalada no boneco, miniatura da persona- 
gem. O raccord acontece tanto pela sincronia entre a manipulação dos bonecos com as imagens já gravadas quanto com o raccord criado pelo próprio olhar do público, que ora prioriza o ator e os bonecos, ora a tela da direita e, em outros momentos, a tela do fundo. O jogo é estabelecido pela sincronicidade ou mesmo por sua falta que possibilita outras analogias.

A Sequência 2 segue uma lógica parecida. Da esquerda para a direita, vemos duas imagens sincrônicas: o ator levantando a perna de seu boneco e um plano dessa mesma perna na tela ao fundo; o boneco movimenta seu olhar para baixo, e logo essa imagem se alterna com a proveniente da câmera subjetiva do boneco, que observa os papéis no chão. Ao mesmo tempo, projeta-se um planomédio, na tela da direita, de todas essas ações, possibilitando uma qualidade diferente da mesma cena realizada no palco. As projeções de imagens ao vivo no teatro propiciam não apenas um ponto de vista diferente da cena ao vivo, mas uma qualidade distinta de imagem, considerando que, principalmente por sua luminosidade, elas invadem a cena de modo quase mágico e são eficientes em "fisgar" o olhar do espectador.

Na Sequência 3, apresenta-se um tipo de raccord que só poderia existir de fato no teatro. Enquanto no palco, o ator-personagem esconde o boneco atrás da casinha - como se olhasse pela janela da casa -, é projetado na tela maior um plano-médio pré-gravado do boneco aparecendo na janela, em alternância com outro plano, também gravado com antecedência, do boneco olhando para dentro da casa, como uma câmera subjetiva. O movimento desse plano com a câmera subjetiva ocorre de baixo para cima, como se observasse a parte interna da casa. No palco, o ator executa o mesmo movimento com a cabeça. É na sincronicidade que acontece o efeito de raccord, com a subjetividade do boneco se transferindo para a subjetividade do ator.

Se até esse momento o público pode não ter percebido a semelhança do boneco com o ator-personagem, configurada pela analogia do figurino, nesse instante da cena, o boneco, antes visto apenas como objeto, se torna definitivamente presente e coisificado, no sentido proposto por Lepecki (2012). Essa evidência é 
ainda maior ao final da cena, exemplificada com a Sequência 4, quando o boneco, por meio da câmera subjetiva, olha para o urso e, em seguida, focaliza o atorpersonagem. Surge, então, um close-up pré-gravado do boneco em crossfade ${ }^{13}$ com um close-up do ator-personagem - também gravado de antemão - e do urso. Essa multiplicidade imagética autoriza o espectador a realizar inúmeras leituras da cena, que vão desde a identificação entre o boneco, o ator-personagem e o urso, até outras mais subjetivas, que consideram o urso como a representação do medo e da frustração a ser superada pelo ator-personagem. Boneco, ator, urso, imagem, todos alcançam o mesmo status na composição da cena: "coisa".

Ainda, no que concerne à cineficação externa em Misanthrofreak, além de trabalhar as imagens com potencial fotogênico, como veremos mais adiante, visou-se priorizar imagens em cena que não se encontrassem determinadas por seu sentido figurativo, como dito anteriormente. Nessa ótica, as projeções estariam em cena prioritariamente pela sensação que elas provocam, e não por sua característica de ilustração representativa. Exemplo disso seria a cena da relação sexual entre o ator-personagem e a boneca inflável, especialmente no momento do orgasmo (Figura 4).

Essa cena se inspira em alguns elementos da montagem dialética, criada por Sergei Eisenstein, na qual a justaposição de imagens e a relação entre os planos, não por continuidade da ação, mas pelo estabelecimento de contrastes e conflitos, gera um cinema não narrativo e não linear. Esse tipo de montagem cinematográfica manipula as imagens de modo que seu andamento não se apoie num agenciamento lógico de tempo, espaço e movimento como concebido pela montagem clássica, mas sim de forma que a justaposição rítmica de imagens independentes propicie sensações e conflitos no âmbito da dialética entre as imagens.

\footnotetext{
${ }^{13}$ Crossfade é um efeito de transição entre duas imagens ou dois sons que se sobrepõem em algum momento durante essa passagem, que é mais suave que uma transição abrupta.
} 
VIS

Revista do Programa de Pós-graduação em Arte da UnB

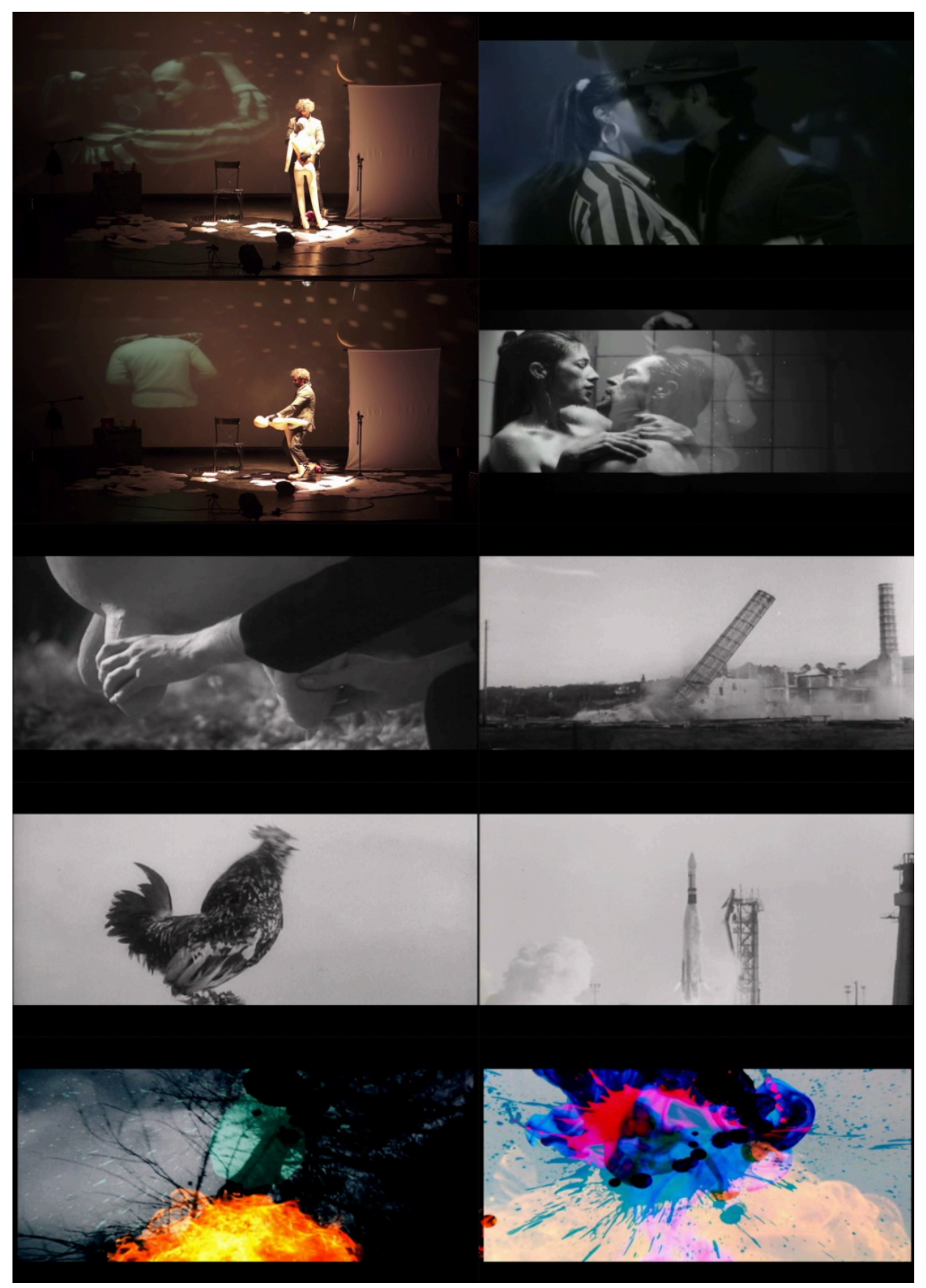

Figura 4 - Sequência com boneca inflável em Misanthrofreak

Além de utilizarmos alguns elementos da montagem dialética por meio de imagens projetadas numa apropriação de cineficação externa, interferimos na encenação de Misanthrofreak também como cineficação interna. A passagem de uma cena para outra, por exemplo, foi determinada mais pelo ritmo do que por uma lógica narrativa em si. A escolha de se trabalhar com cenas independentes deu-se numa perspectiva de privilegiar as múltiplas temporalidades do instante. 
VIS

Revista do Programa de Pós-graduação em Arte da UnB

Há ainda outras inúmeros cineficações internas ao longo do espetáculo, como uma utilização bastante peculiar de plano e contraplano em cena que permite o diálogo do ator com sua própria imagem. Ao mesmo tempo em que o público dispõe de um plano geral da contracena entre o ator e seu alter ego, projetada na tela da direita, a tela ao fundo alterna planos frontais do mesmo ator. Mediante a alternância, um plano pode se referir à personagem, e o contraplano, a seu alter ego. Essa cineficação na cena amplia não apenas o seu efeito visual, mas interfere diretamente na dramaturgia, que se entrelaça à multiplicação temporal propiciada pela imagem, gerando, assim, presença. A imagem revela sua fotogênia.

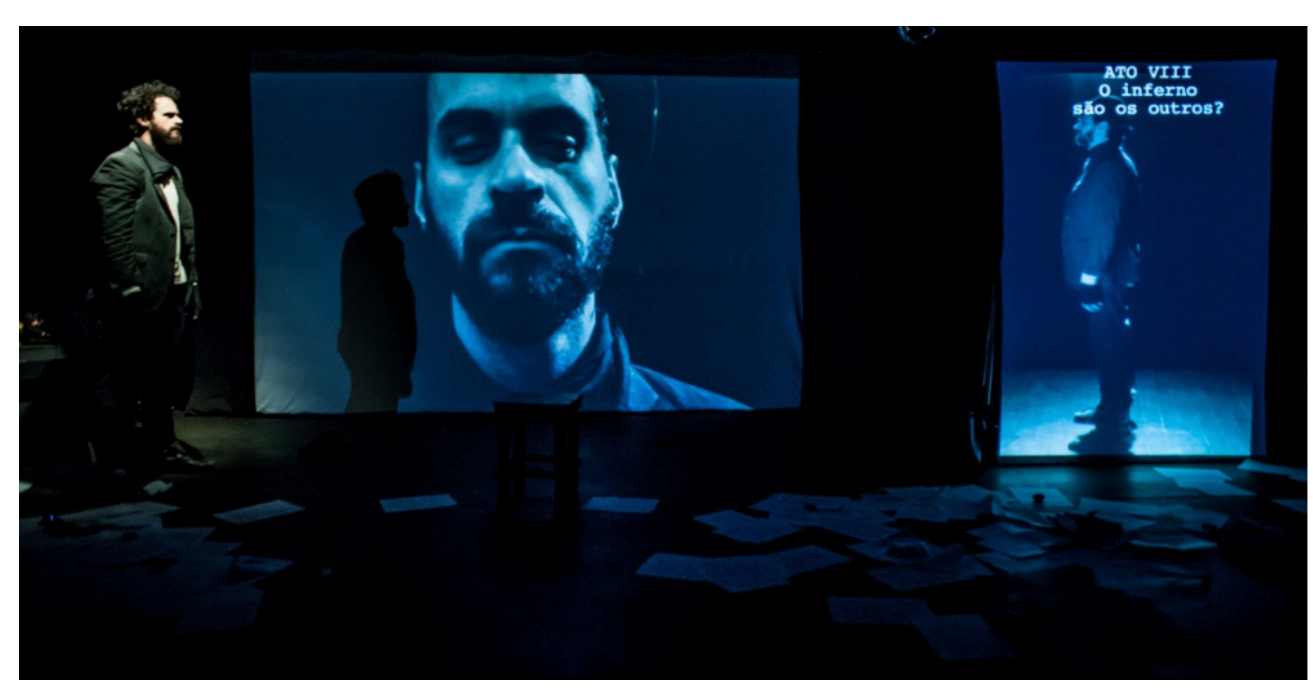

Figura 5 - Plano e contraplano em Misanthrofreak

\section{Fotogenia e efeitos de presença}

A fotogenia, em linhas gerais, seria a capacidade dos seres e objetos, enquanto imagem, de aflorar o afeto. Ou seja, a imagem fotogênica poderia ser tomada como aquela que produz efeitos de presença. Essa predisposição da imagem - ou de uma composição entre corpos e objetos como imagem - poderia remeter a aspectos para além dela própria, transcendendo sua identificação racional. Materializar a fotogenia corresponderia, de certo modo, à materialização também da presença. Ou seja, a imagem fotogenica geraria efeitos de presença que por sua vez, pelo seu agenciamento com ator e outras coisas, propiciaria a produção de presença. 
Segundo Leo Charney, o cineasta e teórico francês Jean Epstein foi quem argumentou na década de 1920 que a essência do cinema derivava da forma do momento sensorial denominado fotogenia - "fragmentos fugazes de experiência que forneciam prazer de um modo que o espectador não conseguia descrever verbalmente ou racionalizar cognitivamente" (2001: 395). Constituiria a noção de fotogenia a ideia da arte-cinema, marcando sua especificidade "como uma forma de arte única da experiência moderna" (Charney, 2001: 395) capaz de envolver o espectador em "momentos de pura imersão na imagem" (Charney, 2001: 395). É interessante notar que, desde tal perspectiva, Epstein aproxima o cinema muito mais da pintura (ou da fotografia) que do teatro ou do drama, os quais também figuram em sua árvore genealógica.

Luis Delluc ${ }^{14}$, definiu a fotogenia como "esse aspecto poético extremo dos seres, das coisas e das almas que acresce sua qualidade moral pela reprodução cinematográfica" (apud Martin, 2003: 26). Assim, ao assumir a noção de fotogenia assumimos, logo, o instante como espaço de experiência e a capacidade mágica de fazer aflorar, a partir da imagem, a ausência ou a poesia nela presente, de revelar elementos das categorias íntimas dos seres, das coisas e do mundo.

A reflexão de Delluc encontra a de Epstein que, além de definir a fotogenia como todo aspecto das coisas, dos seres e das almas que aumenta sua "qualidade moral pela reprodução cinematográfica", sustenta ainda que "todo aspecto que não for majorado pela reprodução cinematográfica não será fotogênico e não fará parte da arte cinematográfica [...] O aspecto fotogênico de um objeto é resultante de suas variações no espaço-tempo" (apud Aumont, 1993: 322-323). Nesse sentido, tanto para Epstein quanto para Delluc, o foco do discurso cinematográfico está mais nas imagens responsáveis por despertar afetos e menos numa narrativa histórica.

\footnotetext{
${ }^{14}$ Luis Delluc, cineasta e crítico francês, resgatou a palavra fotogenia, restrita na época ainda à fotografia, para o cinema, elegendo-a como especificidade do que seria para ele a primeira arte moderna, a arte do futuro. Assim, a fotogenia passa a ser considerada como aspecto poético das coisas, as quais somente o cinema pode revelar como consequência da potente orquestração dos planos e de sua sucessão.
} 
VIS

Revista do Programa de Pós-graduação em Arte da UnB

Gilles Deleuze, ao definir o termo "imagem-afecção", partilha do mesmo pressuposto epistemológico que Epstein e Delluc. Para ele, ao produzir fotogenia, uma imagem consequentemente se constitui como potência afetiva. Esse aspecto fotogênico, ou que é "afetivo por excelência", encontra-se sintetizado, por exemplo, segundo Deleuze (2009: 164), em O Martírio de Joana D’Arc (1928), do cineasta dinamarquês Carl Theodor Dreyer. No filme, o grande plano é explorado em muitas dimensões. Além de uma representação histórica, política e social das personagens (Joana, o bispo, os juízes), há ainda outras camadas que exprimem um elemento interno e subjetivo.

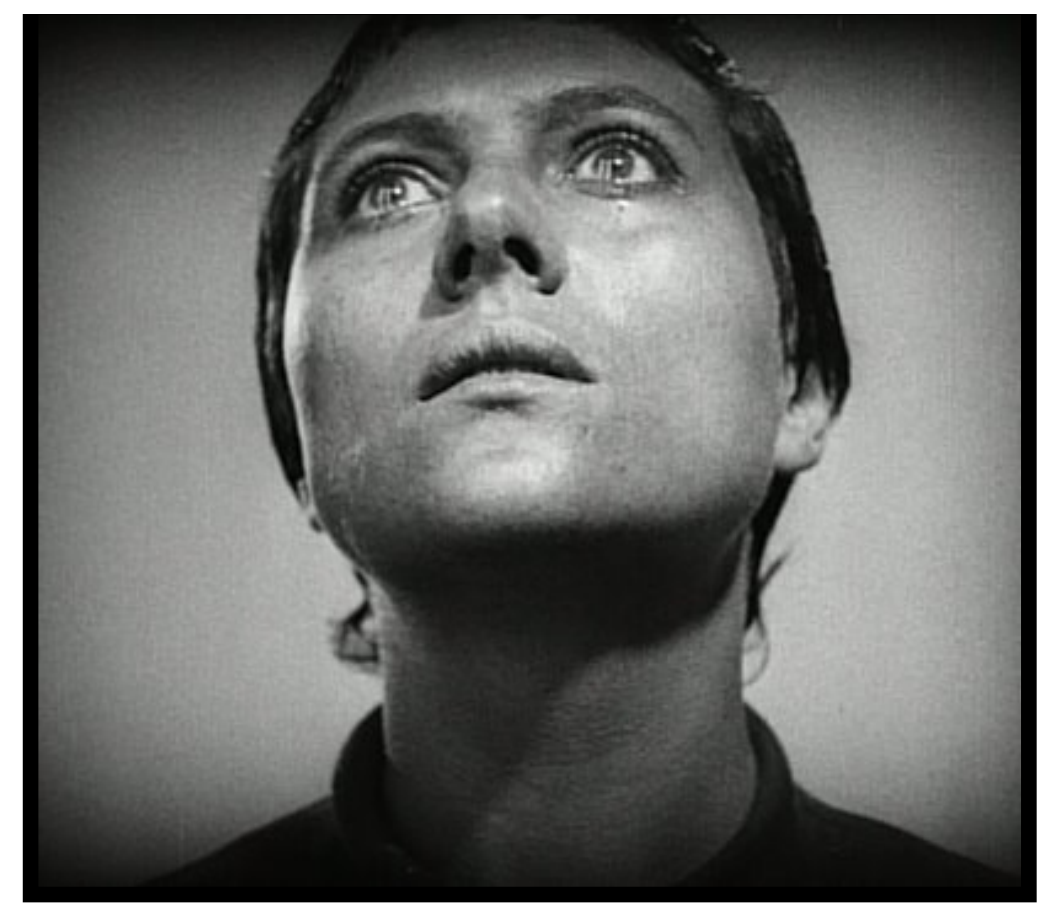

Figura 6. O Martírio de Joana D `Arc, de Carl Theodore Dreyer (1928) ${ }^{15}$

O destaque dado, na figura acima, para o rosto de Joana D'Arc visa evocar, neste texto, um pouco da força expressa pelas imagens em movimento nos grandes planos do filme, um aspecto que ultrapassa o próprio estado das coisas e dos seres. $\mathrm{O}$ interessante ao se pensar a fotogenia nesse filme, e, consequentemente, sua potência afetiva como produtora de presença, é que, apesar de se tratar de uma personagem histórica, o afeto ultrapassa o fato e se instaura a partir do trânsi-

${ }^{15}$ Figura disponível em: <http://artandcultureofmovies.blogspot.com/2010/03/balazs-close-upand-dreyers-passion.html $>$ Acesso em 29 de junho de 2011. 
VIS

Revista do Programa de Pós-graduação em Arte da UnB

to entre a materialidade do corpo da própria atriz e sua personagem. A fotogenia, por meio do grande plano, pode ser entendida como uma tentativa de registrar a materialidade e não necessariamente de representar alguma coisa. Fundamentalmente, seria uma tensão gerada entre a materialidade do rosto e suas possíveis representações enquanto virtualidades.

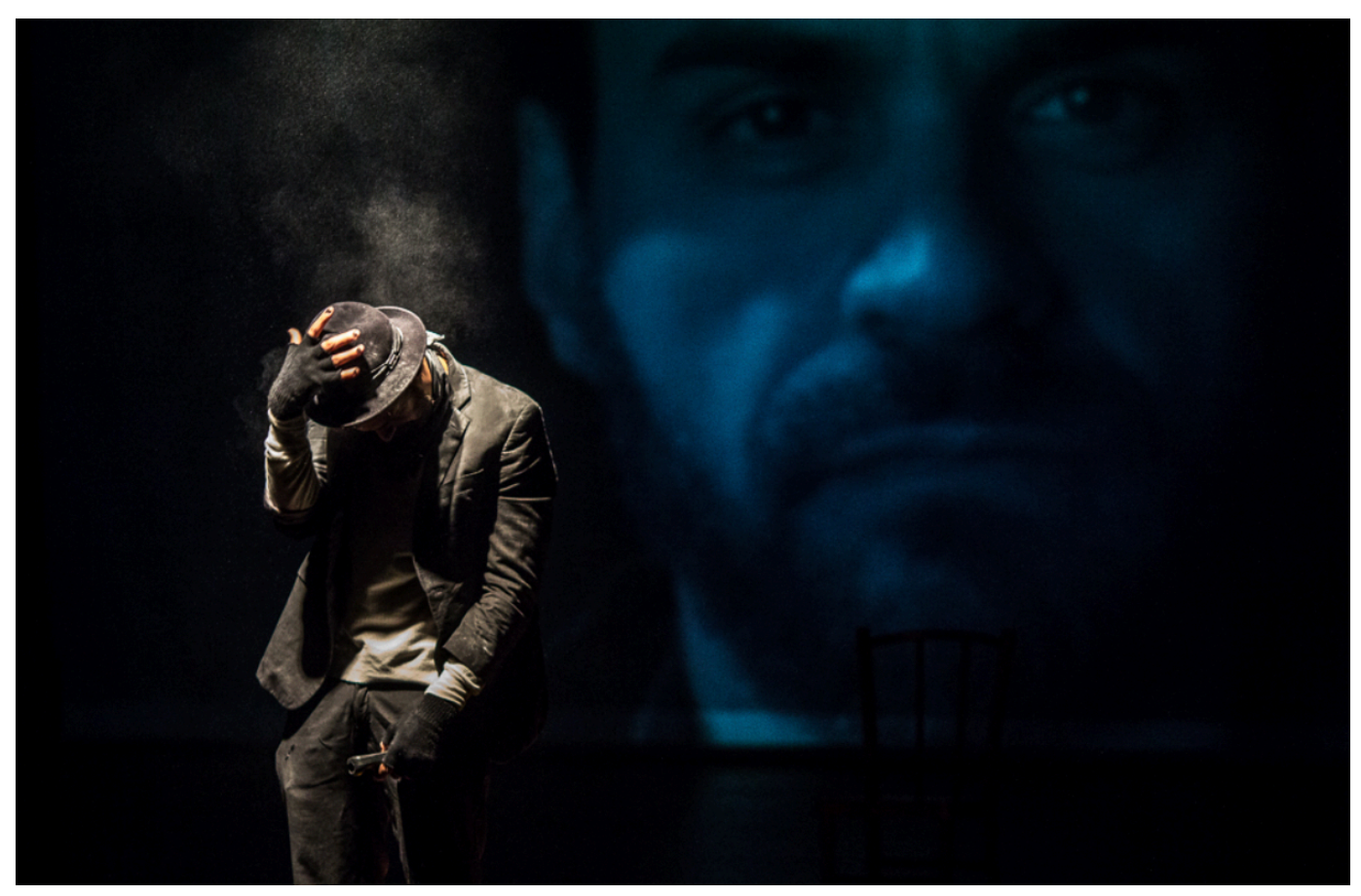

Figura 7. Primeiro plano do ator-performer

De certo modo, a fotogenia veicula o anseio estético de não apenas revelar, mas também esconder. É essa qualidade intrínseca que permite à imagem ser, ao mesmo tempo, ela mesma e outra. Permite-nos ver e sentir para além da identificação e da objetivação, elevando-nos a um estado subjetivo e sublime. Foi também com esse intuito que o grande plano foi explorado em Misanthrofreak, no primeiro contato visual do ator com público.

Essa imagem (Figura 7) nos mostra o momento antes do ator-performer tirar seu chapéu para encarar o público, enquanto um grande plano de seu rosto é projetado na tela principal do palco. Ao tirar o chapéu ele tenta encarar as pessoas que estão na plateia, deixando transparecer seu aparente sofrimento que é potenci- 
alizado pela relação com o primeiro plano projetado e por uma música melancólica que serve de trilha.

Por meio dessa cena é possível fazer a síntese do que procuramos desenvolver neste artigo. Compreendemos, por um lado, como o agenciamento dos efeitos de presença gerados pela imagem (close-up do ator) com a ação simultânea do ator-performer em cena - ocultamento do rosto seguido pelo desvelamento de seu sofrimento quando olha a plateia gerando uma sobreposição e contraste entre um rosto que sofre e outro não - possibilita a multiplicidade de sentidos e quiça a produção de presença. Por outro lado, são dadas pista de como a atuação se faz por meio desse agenciamento quando lemos as impressões do ator-performer:

Enquanto encarava as pessoas na plateia, percebia que quando elas não eram fisgadas pelo meu olhar, elas eram engolidas pelo grande plano de meu rosto projetado. Era praticamente um apelo [...]. E no palco eu tinha consciência disso, da força que tinham a presença da minha imagem projetada em correlação com minha própria presença.

\section{CONCLUSÃO}

Em Misanthrofreak, a interação com novas tecnologias, especialmente com a criação e a projeção de imagens em movimento, desdobra a atuação em diversas camadas, indo do ator-performer presente em carne e osso diante do público - espaço-tempo próprio da teatralidade - ao rosto-afecção em plano detalhe - espaço-tempo próprio do cinema. Fischer, como ator-performer, põe-se em cena entre cineficações externas e internas e, como corpo orgânico que atua, numa relação de despossessão em relação às imagens e objetos, aprende a ausentar-se de um pretenso núcleo produtor de efeitos de presença, dissolvendo-o em "coisas", conforme vimos com Lepecki (2012), que compõem juntamente com ele a cena.

O modo de entender e imprimir a presença dessas coisas em cena - especialmente aquelas ligadas à produção de imagem em movimento - inscreve o espetáculo no campo híbrido da performance e do teatro, favorecendo a produção de efeitos de presença que se dão, justamente, pela desestabilização da teatralidade ao evidenciar o deslocamento do estatuto do ator-performer de certo núcleo de presença da obra. Dessa forma, faz oscilar efeitos de teatralidade e efeitos de per- 
formatividade, convocando o ator-performer a repensar seu espaço de criação e seu jogo de composição com as imagens, os objetos e o testemunho do público.

Além disso, em Misanthrofreak, esse tipo de interação com novas tecnologias impacta não apenas a atuação em sua dimensão de processo criativo, mas também a execução das diversas instâncias tecnológicas (luz, áudio, sonoridades) por um ator autônomo, favorecendo que tais tecnologias atuem nele, afetem suas ações e ampliem outras camadas discursivas da criação.

Essa conclusão aponta, ainda, uma reflexão interessante sobre a emergência de práticas pedagógicas que considerem essa perspectiva de deslocamento e autonomia, em termos de efeitos de presença, na formação do ator-performer na contemporaneidade. Hoje, no que diz respeito ao campo da atuação, grande parte das práticas pedagógicas - consolidadas, especialmente, no teatro dito dramático assumem o corpo orgânico como núcleo irradiador de presença dentro de uma obra. Não seria inoportuno dizer que o contexto do teatro performativo - considerando, nesse caso específico, a interação do teatro com novas mídias e novas tecnologias - convoca desestabilizações desse cenário, apontando novas demandas de presença em cena.

\section{Referências}

AUMONT, Jacques. A imagem. Campinas: Papirus, 1993.

AUMONT, Jacques; MARIE, Michel. Dicionário teórico e crítico de cinema. São Paulo: Papirus, 2003.

BARONE, Luciana Paula Castilho. Projeções poéticas: influências das técnicas com o advento da iluminação, do cinema e do vídeo sobre a arte cênica moderna e contemporânea, 2009. Disponível em: http://www.iar.unicamp.br/lab/luz/ld/C\%EAnica/Copy\%20of\%20Artigos/projeco es_poeticas_influencia_do_advento_das_tecnicas_da_iluminacao_do_cinema_e_d o_video sobre a cenica moderna e contemporanea.pdf. Acesso em: 26 de setembro de 2018.

CHARNEY, Leo. O cinema e a invenção da vida moderna. São Paulo: Cosac Naify, 2001.

. A teoria dos cineastas. Campinas: Papirus, 2004.

DELEUZE, Gilles. Cinema 2 - A imagem-tempo. Lisboa: Assírio \& Alvin, 2006. 
. Cinema 1 - A imagem-movimento. Lisboa: Assírio \& Alvin, 2009.

DIDI-HUBERMAN, Georges. O que vemos, o que nos olha. São Paulo: Ed 34, 1998. . Diante da imagem. São Paulo: Ed 34, 2013.

FÉRAL, Josette. Além dos limites: teoria e prática do teatro. São Paulo: Editora Perspectiva, 2015.

FÉRAL, JOSETTE. Por uma poética da performatividade: o teatro performativo. Revista Sala Preta. São Paulo, vol. 8, 2008, p. 197-210. Disponível em: http://www.revistas.usp.br/salapreta/article/view/57370/60352. Acesso em: $30 \mathrm{de}$ agosto de 2012.

FISCHER, Rodrigo Desider. Uma poética entre o cinema e o teatro: reflexões sobre a presença e a atuação cênica na obra de John Cassavetes. 2015. $212 \mathrm{f}$. Tese (Doutorado em Artes) - Universidade de Brasília, Brasília, 2015. Disponível em: http://repositorio.unb.br/handle/10482/18791?mode=full. Acesso em: 20 de julho de 2018.

LEPECKI, André. 9 variações sobre coisas e performance. Revista Urdimento. Santa Catarina, vol. 2, n. 19, nov. de 2012. pp. 93-99. Disponível em: http://www.revistas.udesc.br/index.php/urdimento/article/view/3194/2327. Acesso em: 12 de janeiro de 2015.

MARTIN, Marcel. A linguagem cinematográfica. São Paulo: Brasiliense, 2003.

MATSUMOTO, Roberta K. Variações sobre teatro e audiovisual. Repertório: Dança \& Teatro, Salvador, ano 20, $\mathrm{n}^{\circ}$ 28, p. 47-67, 2017.1. Disponível em: https://portalseer.ufba.br/index.php/revteatro/article/view/24998. Acesso em: 10 de julho de 2018.

MONTEIRO, Gabriela Lírio Gurgel. Teatro e cinema: uma perspectiva histórica. ArtCultura. Uberlândia, vol. 13, n. 23, jun./dez de 2011. pp. 23-34. Disponível em: http://www.artcultura.inhis.ufu.br/PDF23/gabriela_monteiro.pdfAcesso em: 07 de fevereiro de 2013.

PICON-VALLIN, Béatrice. Teatro híbrido, estilhaçado e múltiplo: um enfoque pedagógico. Revista Sala Preta. São Paulo, vol. 11, n.1, dez 20011, p. 193-211. Disponível em: <https://www.revistas.usp.br/salapreta/article/view/57479/60482> Acesso em: 01 de fevereiro d02/2017

SPINOZA, Benedictus de. Ética. Belo Horizonte: Autêntica, 2009. 